\title{
KENDALI ROBOT BLUETOOTH DENGAN SMARTPHONE ANDROID BERBASIS ARDUINO UNO
}

\author{
Yanolanda Suzantry $\mathbf{H}^{1}$, Yessi Mardiana ${ }^{2}$ \\ yanolanda@unived.ac.id ${ }^{1}$, yessimrd@gmail.com ${ }^{2}$ \\ ${ }^{1}$ Universitas Dehasen Bengkulu, ${ }^{2}$ Universitas Dehasen Bengkulu
}

\begin{abstract}
Abstrak
Robot Mobile adalah konstruksi robot yang ciri khasnya adalah mempunyai actuator berupa roda untuk menggerakkan seluruh badan robot tersebut, sehingga robot dapat melakukan perpindahan posisi dari satu titik ke titik yang lain. Robot Mobile ini dirancang bergerak menggunakan pengontrol Smartphone Android yang memilki aplikasi yang cocok untuk pergerakan robot. Robot ini menggunakan Arduino Uno sebagai sistem pengendalian robot Bluetooth, modul Bluetooth berfungsi sebagai penerimaan perintah yang dikirim melalui Smartphone Android, Motor DC difungsikan sebagai penggerak Robot yang dikendalikan menggunakan Smartphone Android dan aplikasi Boarduino yang di install melalui Playstore. Metode yang digunakan adalah metode eksperimen, penelitian yang dilakukan akan terfokus pada komunikasi antara perangkat Smartphone dengan mikrokontroller Arduino Uno melalui Bluetooth untuk mengendalikan perangkat robot Berdasarkan pengujian koneksi Bluetooth pada robot dapat disimpulkan untuk jangkauan jarak koneksi Bluetooth antara Smartphone dan robot Bluetooth untuk bisa dikendalikan sepenuhnya dengan jarak jangkauan 25 meter, untuk jarak 25-32 meter mengalami penurunan sinyal dan putus-putus, dan lebih dari jarak jangkauan 32 meter akan mengalamai koneksi terputus sehingga robot tidak bisa dikendalikan lagi.

Kata kunci: Robot Mobile, Android, Bluetooth Hc-05, Arduino Uno
\end{abstract}

\section{Abstract}

The Mobile Robot is a robot construction whose characteristic is to have an actuator in the form of a wheel to move the entire body of the robot, so that the robot can shift positions from one point to another. This Mobile Robot is designed to move using an Android Smartphone controller that has an application that is suitable for robot movements. This robot uses Arduino Uno as a Bluetooth robot control system, the Bluetooth module functions as receiving commands sent via an Android Smartphone, a DC Motor is functioned as a controlled Robot drive using an Android Smartphone and Boarduino application installed via Playstore. The method used is the experimental method, the research will focus on communication between smartphone devices and Arduino Uno microcontrollers via Bluetooth to control robotic devices. Based on testing Bluetooth connections on robots, it can be concluded that the Bluetooth connection between the Smartphone and the Bluetooth robot can be fully controlled by a range of 25 meters, for a distance of 25-32 meters has a signal drop and is broken, and more than a range of 32 meters will experience a broken connection so that the robot cannot be controlled anymore.

Keywords: Mobile Robot, Android, Bluetooth Hc-05, Arduino Uno

\section{Pendahuluan}

Robot Mobile atau Mobile Robot adalah konstruksi robot yang ciri khasnya adalah mempunyai actuator berupa roda untuk menggerakkan seluruh badan robot tersebut, sehingga robot tersebut dapat melakukan perpindahan posisi dari satu titik ke titik yang lain. Dalam kasus ini, robot mobile ini dirancang bergerak menggunakan pengontrol yang berasal dari sebuah smartphone android yang memilki aplikasi yang cocok untuk menggerakkan robot tersebut. Koneksi yang digunakan memanfaatkan Bluetooth. Alat ini menggunakan Arduino Uno sebagai penghubung antara perangkat dan smartphone android menggunakan Bluetooth. Alat ini akan bekerja berdasarkan perintah yang diberikan melalui smartphone android dengan aplikasi Boardduino. Motor DC digunakan sebagai penggerak dalam kendali robot, agar mikrokontroller Arduino Uno dapat memberikan suatu instruksi untuk menggerakkan robot, mikrokontroller Arduino Uno memerlukan sebuah program yang diisikan ke dalam mikrokontroller Arduino Uno tersebut. Penulis menggunakan bahasa pemograman board arduino yang menggunakan Arduino Software (IDE). Chip ATmega328 yang terdapat pada Arduino Uno telah di isi dengan program awal yang sering disebut Bootloader. Pada penelitian yang telah dilakukan sebelumnya, peneliti telah membangun sistem kontroller lengan robot berbasis smarthphone android, yang mana aplikasi yang dihasilkan mampu menggerakkan lengan robot 
dengan baik. Aplikasinya juga memiliki sistem pengaman lengan robot dari kerusakan akibat pergerakan motor servo yang tidak sesui dengan daerah kerja lengan robot. Komunikasi data yang diterima arduino mampu ditransmisikan dengan baik dalam radius 15 meter [1]. Selain itu peneliti juga telah melakukan analisa dari rancang bangun mobil remote control dengan smarthphone android menggunakan sensor US-016 berbasis arduino uno, Arduino diprogram menggunakan bahasa C untuk menjalankan motor supaya bergerak sesuai dengan data masukan yang dikirimkan melalui android dan adanya sensor ultrasonik membuat mobil remote control (RC Car) terhindar dari tabrakan atau benturan [2]. Tinjauan pustaka terdahulu juga membahas tentang Sistem Kendali Joystik Ps-2 Wereless pada Robot Beroda Pemindah Barang Berbasis Arduino yang mana hasilnya pemindahan barang dilalukan dengan menggunakan Joystik Ps-2 Wereless hasil yang didapat Jarak maksimum transmisi data dari joystick ke Arduino adalah 8 meter tanpa Halangan dan 6 meter jarak transmisi jika terdapat Halangan [3]. Tinjauan pustaka yang terakhir ini menjelaskan tentang Robot Mobile dikendalikan secara manual oleh operator yaitu dengan penekanan pada tombol keyboard (atas, bawah, kiri, kanan) Pengendalian berikutnya adalah dikendalikan secara otomatis dengan menset waktu pada inputan dalam detik. Dalam hal ini, pengendalian menggunakan personal computer sebagai media kendali mengendalikan mobil robot dapat berjalan baik melalui interfacing [4].

Berdasarkan penelitian di atas peneliti akan membandingkan kendali Robot Mobile menggunakan remote dengan kendali robot berbasis Android maka peneliti akan mengembang sebuah sistem kendali robot bluetooth dengan smartphone android Berbasis Arduino Uno. Dalam penelitian ini ingin dilihat Jarak koneksi bluetooth pada pengendalian robot bluetooth dengan smartphone android dan Pergerakan robot dalam menentukan arah pada pengendalian robot bluetooth. Permasalahan yang akan dibahas oleh peneliti yaitu bagaimana sistem kinerja pada Robot Bluetooth menggunakan Smartphone Android berbasis Arduino Uno. Adapun batasan masalah yang penulisan angkat yaitu Jarak koneksi Bluetooth pada pengendalian robot Bluetooth dengan smartphone android dan pergerakan robot dalam menentukan arah pada pengendalian robot Bluetooth. Tujuan utama dalam penelitian yang akan dicapai dari penulisan adalah tercipatanya sebuah kendali Robot Bluetooth dengan Smartphone Android Berbasis Arduino Uno.

\section{Metode}

\subsection{Metode Penelitian}

Metode penelitian yang dilakukan studi literatur dan eksperimen laboratorium. Penelitian yang dilakukan akan terfokus pada komunikasi antara perangkat smartphone dengan mikrokontroller Arduino melalui Bluetooth untuk mengendalikan perangkat robot. Dari hasil eksperimen nantinya akan disimpulkan jarak koneksi bluetooth pada pengendalian robot bluetooth dengan smartphone android berbasis Arduino Uno.

\subsection{Instrumen Perangkat Lunak dan Perangkat Keras}

Dalam eksperimen kendali Robot Bluetooth dengan Smartphone Android adapun alat dan bahan yang digunakan adalah :

1. Perangkat Lunak (Software) yang digunakan dalam penelitian ini adalah Boardduino dan Arduino IDE

2. Perangkat Keras (Hardware) yang digunakan dalam penelitian ini dapat di lihat pada Tabel 1 berikut:

\begin{tabular}{|c|c|c|}
\hline \multicolumn{3}{|c|}{ Tabel 1. Perangkat keras (hardware) } \\
\hline No & Jenis & Spesifikasi \\
\hline 1 & $\begin{array}{l}\text { Smartphone Android Xiaomi } \\
\text { MI 4LTE }\end{array}$ & $\begin{array}{l}\text { - Processor Quad Core Max 2.45GHz } \\
\text { - Android Version 6.0.1 MMB29M } \\
\text { - RAM 2.00 GB } \\
\text { - Internal Memori } 16 \mathrm{~GB} \\
\text { - Bluetooth Version 6.0.1 (23) }\end{array}$ \\
\hline 2 & Robot Bluetooth & $\begin{array}{l}\text { - } 1 \text { Arduino UNO } \\
\text { - } 1 \text { Bluetooth Modul HC-06/HC-05 } \\
\text { - } 1 \text { IC L293D } \\
\text { - } 2 \text { Motor DC }\end{array}$ \\
\hline 3 & Laptop Acer Aspire 4739 & $\begin{array}{l}\text { - Processor Inte }{ }^{\circledR} \text { Core }^{\mathrm{TM}} \text { i3 CPU M370 @ } 2.40 \mathrm{GHz} \\
\text { - Harddisk } 320 \mathrm{~GB}\end{array}$ \\
\hline
\end{tabular}




\begin{tabular}{|l|l|l|}
\hline & & $\bullet$ VGA Intel® HD Graphics \\
& & $\bullet$ RAM 2.00 GB DDR3 Memory \\
\hline
\end{tabular}

\subsection{Metode Perancangan Sistem}

\subsubsection{Blok Diagram Global}

Blok diagram global yang digunakan dalam perancangan penelitian ini adalah sebagai berikut:

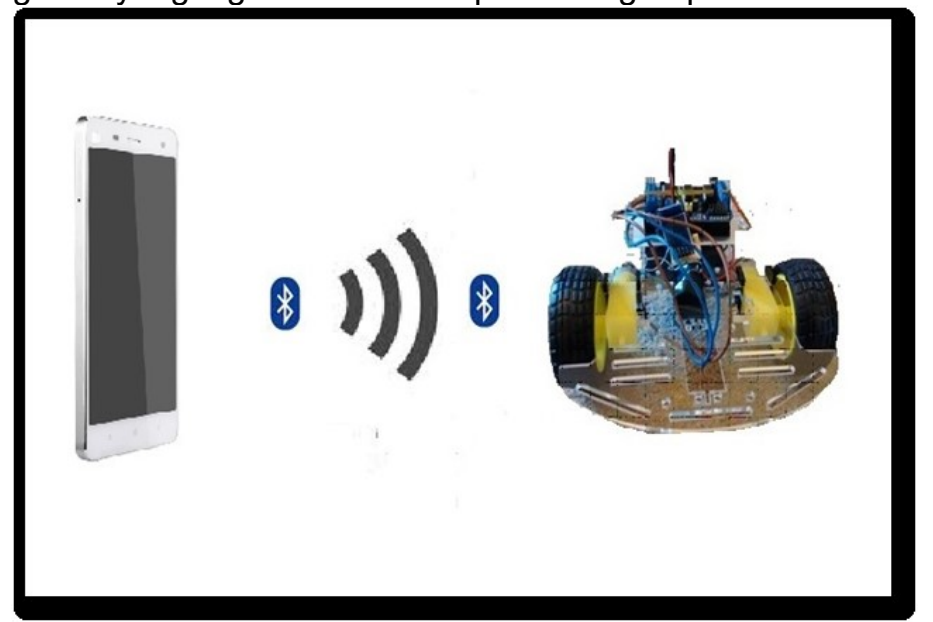

Gambar 1. Blok Diagram Global

Pada gambar 1 blok diagram global, dengan menggunakan aplikasi Boarduino yang di install pada smarphone android, smartphone Android bisa terhubung dengan Arduino dengan menggunakan modul Bluetooth yang terpasang pada Arduino dan akan memberi perintah untuk menggerakkan motor DC.

\subsubsection{Blok Diagram Rangkaian}

Gambar 2 dibawah ini adalah gambar diagram rangkaian robot. Blok diagram rangkain kendali Robot Bluetooth dengan Smartphone Android Berbasis Arduino UNO terdiri dari rangkaian Smartphone, Modul Bluetooth, arduino, IC L293D, Motor DC.

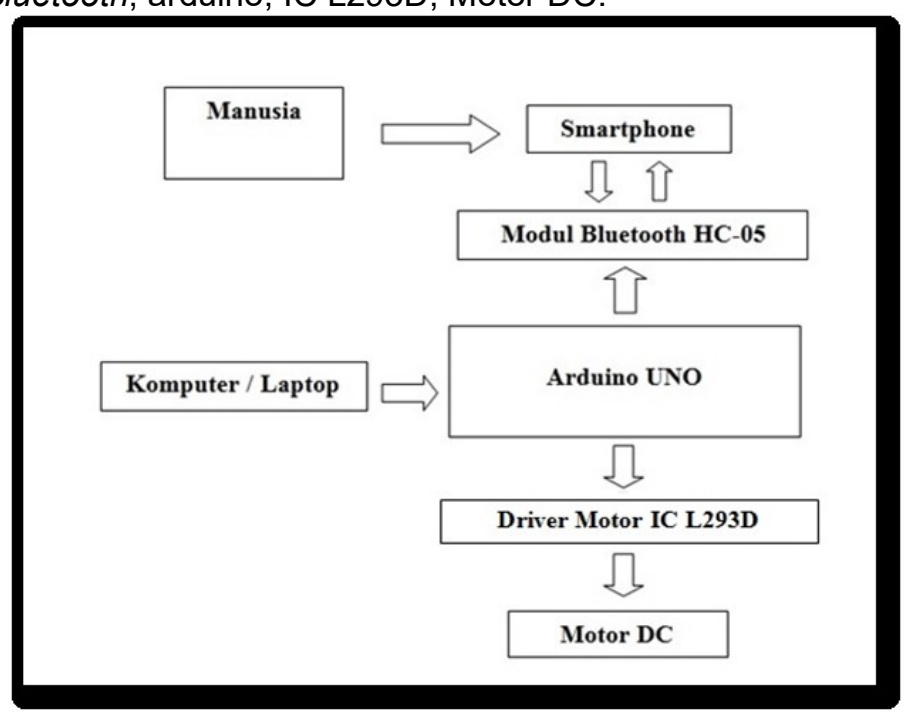

Gambar 2. Blok Diagram Global

Smartphone android berfungsi sebagai pengendali Robot memanfaatkan sebuah teknologi komunikasi nirkabel yang akan terhubung pada modul Bluetooth. Arduino UNO berfungsi sebagai pengolahan data berupa program yang di upload dari komputer dengan menggunakan serial USB. Komputer, digunakan sebagai perancangan program untuk pengendalian robot Bluetooth berbasis Arduio UNO. Driver Motor IC L293D digunakan untuk membuat driver H-bridge untuk 2 buah motor 
DC (Direct Current). Motor DC berfungsi sebagai penggerak badan Robot yang dikendalikan menggunakan smartphone.

\subsubsection{Desain Rangkaian}

Rancangan penelitian yang akan dilakukan yaitu mendesain rangkaian kendali robot Bluetooth dengan Smartphone Android Berbasis Arduino Uno, dapat dilihat pada Gambar 3 di bawah ini :

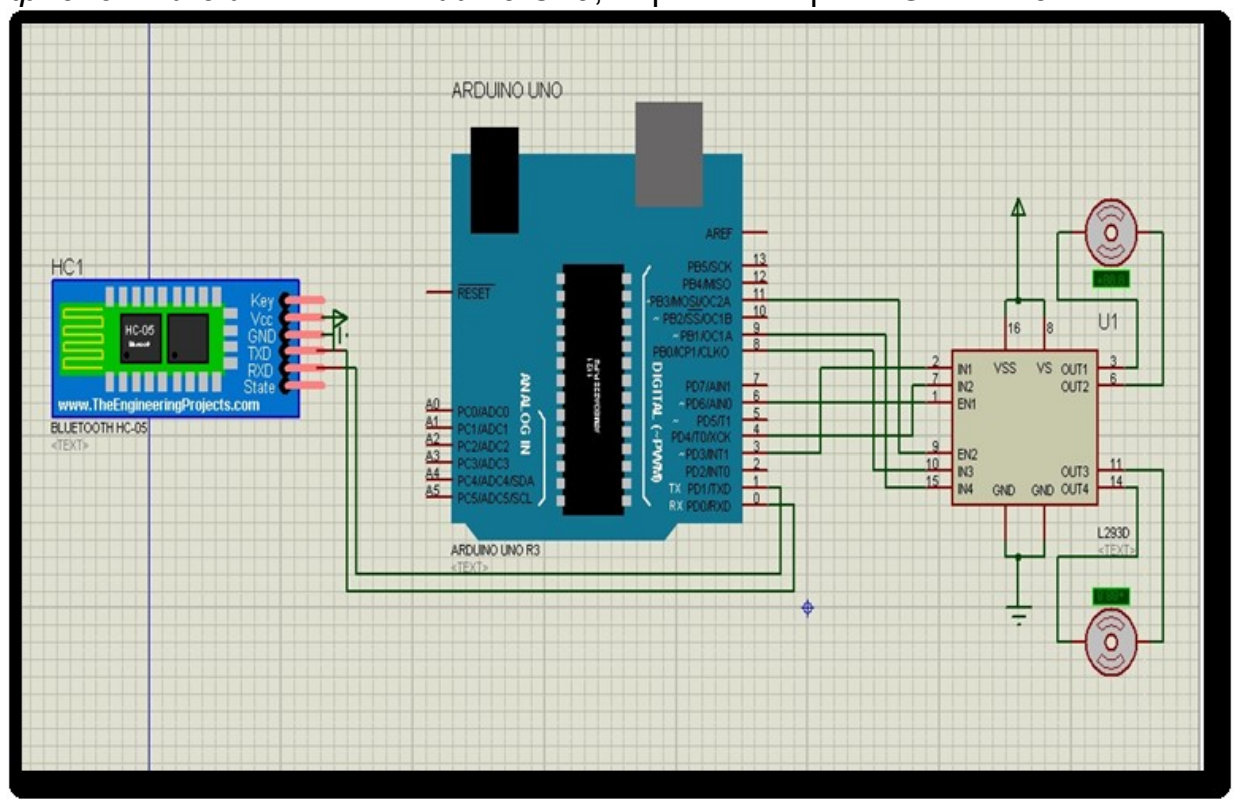

Gambar 3. Desain Rangkaian Kendali Robot Bluetooth dengan Smartphone

Untuk medapatkan sebuah desaian rangkaian Kendali Robot Bluetooth dengan Smartphone hubungkan pin 2A pada modul Arduino Uno ke pin EN2 pada modul Motor DC, pin 1A pada modul Arduino Uno ke pin IN4 pada modul Motor DC, pin P1 CLK 0 pada modul Arduino Uno ke pin IN3 pada modul Motor DC, pin PDC/ AND pada modul Arduino Uno ke pin EN1 pada modul Motor DC, pin TOX CK pada modul Arduino Uno ke pin IN2 pada modul Motor DC, dan pin PD3/ INT 1 pada modul Arduino Uno ke pin IN1 pada modul Motor DC, lalu pin PD1 /TXD pada modul Arduino Uno ke pin RXD pada modul Bluetooth HC-05 dan yang terakhir hubungkan pin PDO / RXD pada modul Arduino Uno ke pin TXD pada modul Bluetooth HC-05.

\subsubsection{Prinsip Kerja Sistem}

Prinsip pengendalian robot Bluetooth membutuhkan 1 unit smartphone yang berfungsi sebagai pengirim perintah control arah gerak dengan mengirim data Bluetooth dalam sistem aplikasi control Bluetooth. Didalamnya sudah diberikan data logika yang akan dikirimkan melalui HC-05 dan masuk kedalam sistem mikrokontroller yaitu Arduino Uno. Arduino Uno akan bekerja berdasarkan alur perangkat lunak. Data yang sudah diolah oleh Arduino Uno akan membuat keluaran pada Port berlogika dan memberikan data pada fruit Motor shield, lalu motor DC akan menentukan arah putar motor.

\section{Hasil dan Pembahasan}

Hasil analisa kendali robot Bluetooth dengan Smartphone Android berbasis Arduino Uno, pada Robot ini menggunakan Arduino Uno sebagai sistem pengendalian robot Bluetooth $\mathrm{Hc}-05$, modul Bluetooth digunakan sebagai penerimaan perintah yang dikirim melalui Smartphone Android, motor DC difungsikan sebagai penggerak Robot yang dikendalikan menggunakan Smartphone Android menggunakan aplikasi Boarduino yang di install melalui playstore. Dalam penelitian ini penulis mendapatkan hasil dapat dilihat pada Gambar 4 di bawah ini : 


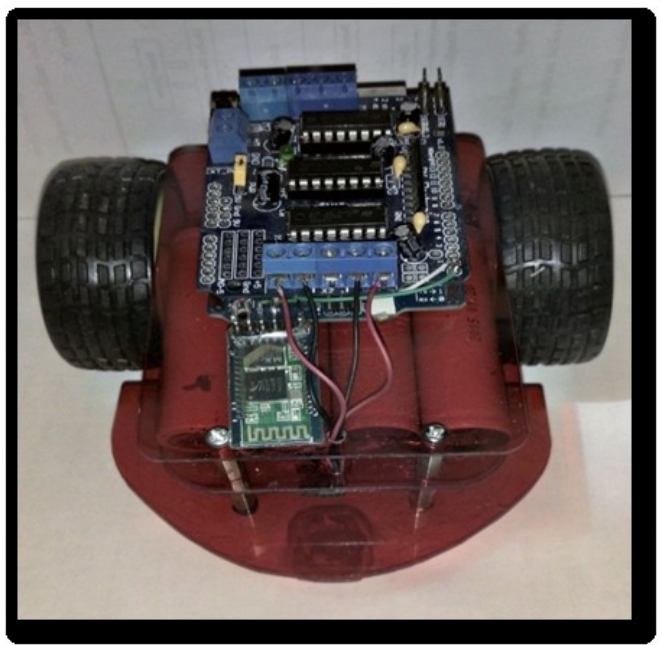

Gambar 4. Hasil Robot Mobil yang Sudah di Rangkai

Untuk keterangan konfigurasi kabel sebagai berikut, Pin 5V pada Arduino Uno dihubungkan pada pin VCC modul Bluetooth HC-05, pin GND pada Arduino Uno dihubungkan pada pin GND modul Bluetooth $\mathrm{HC}-05$, pin RX pada Arduino Uno dihubungkan pada pin TX pada modul Bluetooth $\mathrm{HC}-05$, pin TX pada Arduino Uno dihubungkan pada pin RX pada Bluetooth HC-05, motor DC pada bagian kiri dihubungkan pada M4 driver motor shield L293D, motor DC pada bagian kanan dihubungkan pada M3 driver motor shield L293D, untuk tegangan yang dibutuhkan board Arduino Uno menggunakan 4 buah batre 3,7 Volt dipasang seri dan paraler dan menghasilkan tegangan 7,4 Volt yang dihubungkan pada jack Arduino Uno.

Setelah menghasilkan robot mobil maka kita mulai menginstal dan penggunaan aplikasi Boarduino digunakan sebagai tombol pengendalian robot dengan memanfaatkan koneksi Bluetooth untuk memberikan perintah arah pada pergerakan robot. Adapun cara penginstalan dan penggunaan aplikasi Boarduino ini adalah install aplikasi Boarduino yang dilakukan dengan cara download melalui playstore. Melakukan penyandingan Bluetooth $\mathrm{HC}-05$ dengan Smartphone Android dengan memasukkan kode standar dari modul Bluetooth HC-05 yaitu 1234. Buka aplikasi Boarduino yang telah di install, tekan pada bagian more lalu pilih Arduino Bluetooth RC Car. Klik pada lambang Bluetooth lalu pilih nama Bluetooth $\mathrm{HC}-05$ makan koneksi Bluetooth sudah terhubung dan robot siap di gerakkan. Tampilan pengendalian robot menggunakan aplikasi Boarduino dapat dilihat pada gambar 5 di bawah ini :
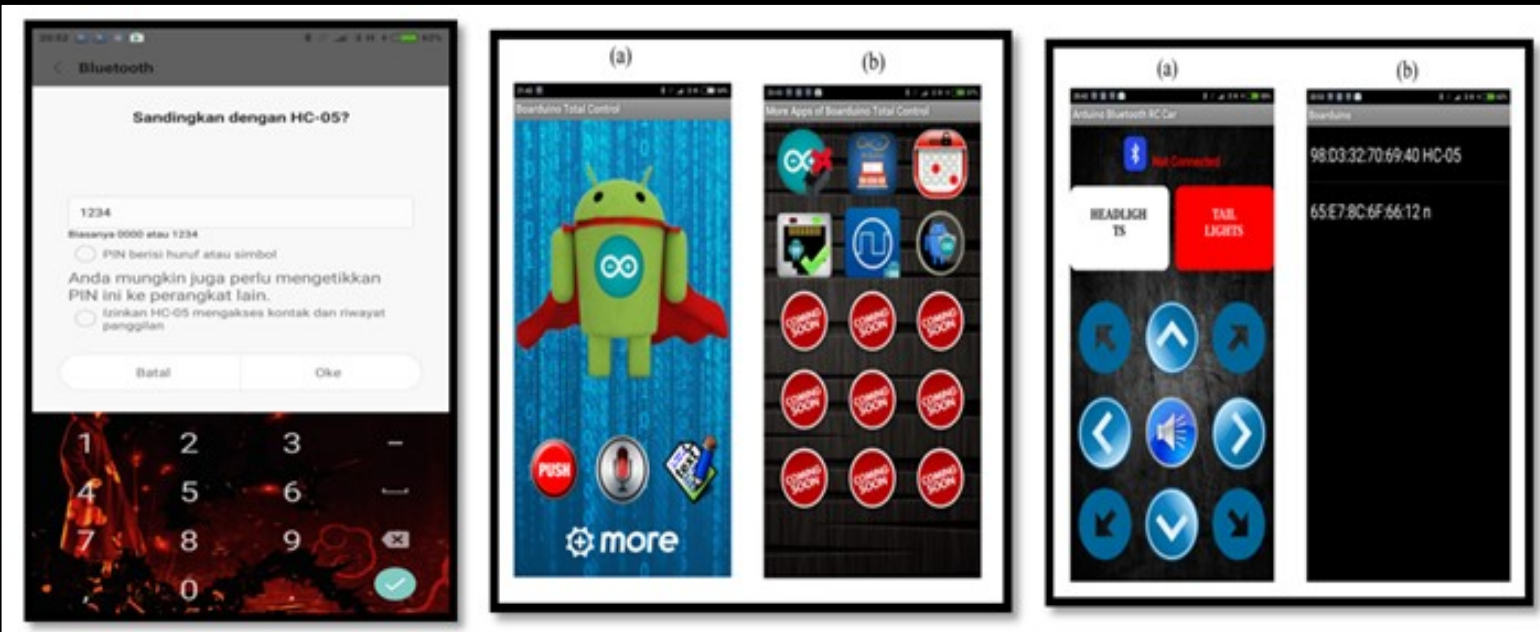

Gambar 5. Tampilan Pengendali Robot Mobil Menggunakan Aplikasi Boarduino

Memasuki tahapan pengujian, pengujian yang dilakukan adalah pengujian jarak koneksi Bluetooth antara Smarthphone dan robot sehingga di dapat jarak jangkauan koneksi yang maksimal untuk pengendalian robot. Dan akan mendapat hasil sebagai berikut saat jarak koneksi Bluetooth 
terhubung robot dapat dikendalikan, Saat koneksi Bluetooth terputus-putus robot susah dikendalikan, Saat koneksi Bluetooth terputus robot tidak dapat dikendalikan. Berikut adalah tabel hasil pengujian jarak koneksi Bluetooth pada robot.

Tabel 2. Hasil Pengujian Jarak Koneksi Bluetooth Pada Robot

\begin{tabular}{|c|c|l|l|}
\hline Percobaan & Jarak (meter) & \multicolumn{1}{c|}{ Hasil } & \multicolumn{1}{c|}{ Keterangan } \\
\hline 1 & 2 & Terhubung & Robot dapat dikendalikan \\
\hline 2 & 4 & Terhubung & Robot dapat dikendalikan \\
\hline 3 & 6 & Terhubung & Robot dapat dikendalikan \\
\hline 4 & 8 & Terhubung & Robot dapat dikendalikan \\
\hline 5 & 10 & Terhubung & Robot dapat dikendalikan \\
\hline 6 & 12 & Terhubung & Robot dapat dikendalikan \\
\hline 7 & 14 & Terhubung & Robot dapat dikendalikan \\
\hline 8 & 16 & Terhubung & Robot dapat dikendalikan \\
\hline 9 & 18 & Terhubung & Robot dapat dikendalikan \\
\hline 10 & 20 & Terhubung & Robot dapat dikendalikan \\
\hline 11 & 22 & Terhubung & Robot dapat dikendalikan \\
\hline 12 & 24 & Terhubung & Robot dapat dikendalikan \\
\hline 13 & 26 & Putus-Putus & Robot susah dikendalikan \\
\hline 14 & 28 & Putus-Putus & Robot susah dikendalikan \\
\hline 15 & 30 & Putus-Putus & Robot susah dikendalikan \\
\hline 16 & 32 & Putus-Putus & Robot susah dikendalikan \\
\hline 17 & 34 & Terputus & Robot tidak dapat dikendalikan \\
\hline 18 & 36 & Terputus & Robot tidak dapat dikendalikan \\
\hline 19 & 38 & Terputus & Robot tidak dapat dikendalikan \\
\hline 20 & 40 & Terputus & Robot tidak dapat dikendalikan \\
\hline
\end{tabular}

Berdasarkan hasil tabel diatas dapat disimpulkan untuk jangkauan jarak koneksi Bluetooth HC-05 antara Smartphone Android dan robot Bluetooth untuk dapat dikendalikan sepenuhnya dengan jarak jangkauan maksimal 25 meter, untuk jarak antara 25 meter sampai dengan jarak 32 meter mengalami sinyal yang kurang baik yaitu terputus-putus, dan lebih dari jangkauan 32 meter akan mengalamai koneksi yang mana sinyalnya terputus sehingga robot tidak dapat dikendalikan lagi. Berdasarkan analisa penulis kondisi sinyal pada Bluetooth mempengaruhi komunikasi transfer data dalam pengendali robot Bluetooth, jarak jangkauan sinyal Bluetooth tergantung pada spesifikasi Modul HC05 untuk pengirim atau penerima data pada pergerakan robot.

\section{Kesimpulan dan Saran}

Setelah perancangan, pengujian dan analisanya, maka dapat diambil beberapa kesimpulan tentang sistem kendali robot Bluetooth dengan Smartphone Android berbasis Arduino Uno yang dibuat oleh penulis :

a) Perancangan robot Bluetooth meliputi perancangan desain body robot, perancangan konfigurasi kabel antara Arduino Uno, modul Bluetooth $\mathrm{HC}-05$, driver motor shield, motor DC sehingga robot Bluetooth dapat dikendalikan user melalui Smartphone Android.

b) Dalam pergerakan robot dapat diketahui hasil program pada Arduino Uno untuk pengendalian robot Bluetooth yang dapat di kendalikan oleh user melalui Smartphone Android.

c) Berdasarkan koneksi antara robot Bluetooth dan Smartphone Android dapat diketahui jarak maksimalnya sebesar 24 meter dan status terhubung sebagian robot masih bisa dikendalikan.

d) Berdasarkan koneksi antara robot Bluetooth dan Smartphone Android dalam jarak lebih dari 32 meter robot tidak dapat dikendalikan.

Pengembangan sistem kendali robot Bluetooth dengan Smartphone Android berbasis Arduino Uno selanjutnya dapat menggunakan sistemkendali Google Voice menggunakan Smarthphone Android.

\section{Terima Kasih}

1. Penelitian ini dibiayai oleh Direktorat Jenderal Penguatan Riset dan Pengembangan, Kementerian Riset, Teknologi dan Pendidikan Tinggi melalui Penelitian Dosen Pemula (PDP) Tahun Anggaran 2018. 
2. Bapak Prof. Dr. agr. Ir. Johan Setianto selaku Rektor Universitas Dehasen Bengkulu.

3. Bapak Khairil, M. Kom selaku Kepala UPT Puskom dan Seluruh staf Laboratorium UPT Puskom Universitas Dehasen Bengkulu.

4. Lembaga Penelitian dan Pengabdian Masyarakat Universitas Dehasen Bengkulu atas segala arahan, bantuan dan fasilitasnya.

5. Civitas akademika Universitas Dehasen Bengkulu atas segala dorongan, semangat dan dukungannya.

6. Semua pihak yang telah membantu menyelesaikan penelitian ini yang tidak dapat penulis sebutkan satu persatu.

\section{Daftar Pustaka}

[1] Putra Wiratama Anggun Yoel. 2015. Kontroler Lengan Robor Berbasis Smarthphone Android. Tugas Akhir Program Studi Teknik Elektro. Jurusan Teknik Elektro Fakultas Sains Dan Teknologi Universitas Sanata Dharma Yogyakarta.

[2] Fadilah Ayyub. 2017. Rancang Bangun Mobil Remote Control Dengan Smarthphone Android Menggunakan Sensor US-016 Berbasis Arduino Uno. Departemen S1 Fisika Fakultas Matematika Dan Ilmu Pengetahuan Alam. Universitas Sumatra Utara Medan.

[3] Purwandi, Wahyu., 2013. Sistem Kendali Jarak Jauh dengan Handphone Menggunakan Pengenal Suara Microsoft SAPI 5.3". Jurnal ELTEK, Vol 11. No. 01, April 2013, ISSN 1693-4024, pp 42-54.

[4] Wardhana, Wisnu, Walid. 2007. Sistem Kendali Jarak Jauh Mobil Robot Menggunakan Personal Komputer. Fakultas Teknik dan IImu Komputer. Jurusan Teknik Informatika. Universitas Komputer Indonesia. 